\title{
Monitoring of the Rice Cropping System in the Mekong Delta Using ENVISAT/ASAR Dual Polarization Data
}

\author{
Alexandre Bouvet, Thuy Le Toan, and Nguyen Lam-Dao
}

\begin{abstract}
The rice cropping system in Asia is undergoing major changes to cope with increasing demography and changing climate, making rice monitoring a critical issue. Past studies have demonstrated the use of C-band synthetic aperture radar (SAR) data to map rice areas. The methods were based on the temporal change of intensity backscattering coefficient of vertically or horizontally co-polarized data (VV or $\mathrm{HH})$. In this paper, we assess the use of the $\mathrm{HH} / \mathrm{VV}$ polarization ratio derived from Advanced SAR (ASAR) data from ENVISAT data for the production of rice paddy maps. The approach is based on past knowledge on the polarization behavior of rice canopy, i.e., VV backscattering is much lower than HH during a large part of the rice season, due to the attenuation of the wave by the vertical structure of the plants. The methodology is developed for the Mekong Delta, Vietnam, where a complex cropping pattern is found (one to three crops of rice per year). The approach includes a statistical analysis of the $\mathrm{HH} / \mathrm{VV}$ distributions of rice and non-rice classes at different dates. The analysis results confirm that $\mathrm{HH} / \mathrm{VV}$ can be used as classifier and point out the need for relevant speckle filtering prior to classification. A classification method is developed and applied to single- and multidate data sets. The methods are tested at one district of the province of An Giang and extended to the whole province. Comparisons of the mapping results to geographic-information-system land-use data and official agricultural statistics show very good agreement. The method will be further applied to the entire Mekong Delta.
\end{abstract}

Index Terms-(Advanced) Synthetic Aperture Radar (ASAR), Mekong Delta, polarization ratio, rice mapping.

\section{INTRODUCTION}

$\mathbf{T}$ HE PRIMARY food source for more than half of the world's population is rice (Oryza sativa). Demand for rice is projected to increase by nearly $70 \%$ until 2025 [1]. At the same time, population increase and intensification of economic development are leading to the decline of rice harvested area. Changes in paddy rice cropland distribution and management intensity (multicropping, water management, fertilizer use, and cultivars) are projected to intensify over the coming decades. These changes in rice area and cultural practices can have a

Manuscript received February 25, 2008; revised July 10, 2008. Current version published January 28, 2009.

A. Bouvet and T. Le Toan are with the Centre d'Etudes Spatiales de la Biosphère, 31401 Toulouse, France (e-mail: Alexandre.Bouvet@cesbio. cnes.fr; thuy.letoan@cesbio.cnes.fr).

N. Lam-Dao is with the GIS and Remote Sensing Research Center, Ho Chi Minh City Institute of Resources Geography, Ho Chi Minh City, Vietnam, with the University of Southern Queensland, Toowoomba, Qld 4350, Australia, and also with the Vietnam National University, Ho Chi Minh City, Vietnam.

Digital Object Identifier 10.1109/TGRS.2008.2007963 significant impact on the global climate, since irrigated rice fields are among the major sources of methane $\left(\mathrm{CH}_{4}\right)$ emissions and because of the importance of the world rice area (1.57 million $\mathrm{km}^{2}$ in 2007 [2]). To monitor changes in the rice production area and cultivation intensity, satellite remote sensing data constitute a unique tool which can provide timely and consistent spatial and temporal coverage needed at regional to global scales.

Among remote sensing methods, only radar imaging systems are not limited by cloud coverage in tropical and subtropical regions where most rice is grown. Using optical sensors, high temporal repeat frequency is required in order to have cloudfree observations. This could be done with medium-resolution (about $250 \mathrm{~m}-1 \mathrm{~km}$ ) sensors such as the Moderate Resolution Imaging Spectroradiometer (MODIS), VEGETATION, or Medium Resolution Imaging Spectrometer (MERIS). Investigations on the use of time series of vegetation and water indices (e.g., normalized difference vegetation index, enhanced vegetation index, and normalized difference water index) derived from VEGETATION [3] and MODIS [4]-[6] have been carried out to map paddy rice agriculture in Asia. In [5], the spatial distribution of paddy rice in South and Southeast Asia was reported using MODIS. Yet, ancillary information (cropping intensity) was needed to calculate the sown area. Furthermore, results in the Mekong Delta in [5] are considered by the authors as erroneous, probably because the flood pattern disturbs the rice detection. In [4], cropping systems could be identified in the Mekong Delta with MODIS data. However, prior identification of rice-e.g., by existing databases-is needed in order to remove confusion between rice and other vegetation types. Compared to optical data, radar data have the advantage to distinguish well-developed rice from water surfaces and other crops, because of the specific radar backscattering physics of inundated vegetation. The radar data have, in addition, higher spatial resolution (about $30 \mathrm{~m}$ ), allowing observations with more details on the individual fields.

In terms of electromagnetic interaction mechanisms between radar waves and vegetation canopy, the radar backscatter can be approximated by the sum of three main components: the volume scattering, the scattering from the ground attenuated by the vegetation layer, and the multiple scattering between the volume and ground. The latter term is often negligible compared to the volume and ground scattering, with the exception of inundated fields, for which the volume-ground scattering becomes important. At C-band, theoretical studies using a coherent scattering model of rice canopy based on 
Monte Carlo simulations [7], [8] have demonstrated that the copolarized backscatter from rice fields covered by a water layer is dominated by the double bounce volume-ground interaction, with the dominant scatterers in the volume being the plant stems. Simulations of the temporal backscatter at $\mathrm{HH}$ and VV polarizations and at $23^{\circ}$ of incidence angle have shown a significant increase of the backscattering coefficient during the vegetative phase which lasts 40-70 days depending on the rice varieties. The backscatter then decreases slightly during the reproductive phase until harvest. This temporal behavior was effectively reported in a number of studies using ERS-1/2 and RADARSAT-1 data in Japan [9], Indonesia [7], [10], China [11], India [12], [13], the Philippines [14], Thailand [15], [16], and Vietnam [17], [18]. Backscatter was found increasing by more than $10 \mathrm{~dB}$ at $\mathrm{HH}$ and $\mathrm{VV}$ from the beginning of the growth cycle (flooded fields) to the maximum value around the end of the vegetative phase. In past studies, the use of $\mathrm{HH}$ or VV as classifiers was found unsuitable for rice classification in regions where adjacent fields can have shifted calendars. Instead, the unique temporal behavior has been exploited in rice mapping methods, in which the classifiers are the temporal change of $\mathrm{HH}$ or VV backscattering. Such methods have been proven effective at a number of sites [7], [10], [14], [17], [18].

The previous studies have also pointed out the conditions under which these temporal change methods can be applied. The most important conditions are 1) a sufficient number of images during the rice cycle, with a minimum number of three per cycle being indicated [7], and 2) that the rice fields are continuously flooded from the beginning of the cycle until two weeks before harvest. The first condition is met with traditional rice varieties (cycle of 120-150 days), which allows three or more scenes to be acquired with the current satellite repeat cycle-e.g., 35 days of the Advanced Synthetic Aperture Radar (ASAR) on board the Environmental Satellite (ENVISAT). The second condition is well suited to traditional water management, for which a persistent layer of water is maintained on the fields either by rainfed or intermittent irrigation.

Comparatively to copolarized backscatter, much less effort has been put on the use of cross-polarized backscatter in rice applications. Measurements with a multifrequency polarimetric scatterometer on an experimental paddy field in Japan [19] have shown that C-band cross-polarized backscatter is correlated to some rice biophysical parameters (leaf area index and canopy height) and has a temporal behavior similar to that of copolarized backscatter. However, the HV value and its temporal change, being mostly governed by volume scattering, are not specific to rice, but also to other crops in the same scene. With the launch of ENVISAT in 2002, it has been the first time that a satellite SAR system could provide cross-polarized C-band data, as part of ASAR dual-polarization products $(\mathrm{HH}$ and HV or VV and VH). However, only very few studies using ASAR have been carried out to confirm the potential of $\mathrm{HV}$ or $\mathrm{VH}$ for rice monitoring. In [20], $\mathrm{HV} / \mathrm{HH}$ has been related to plant biomass at three dates during the vegetative stage in rainfed rice fields in West Bengal, India, and in [21], a rice map was produced in Guangdong province, China, using a ratio between $\mathrm{HH}$ at one date at the end of the growth cycle and $\mathrm{HV}$ at another date at the beginning of the cycle. Both results rely on few data sets and need to be assessed at other test sites. Theoretical modeling studies are also needed in order to provide a better understanding of the interactions between cross-polarized waves and the inundated rice canopy.

As stated previously, in recent years, changes in cultural practices have been observed in different regions of the world. The rice growth region in the Mekong Delta in Vietnam is a good example of changes from the traditional to modern rice cultivation system in the last ten years. A multiple cropping system is implemented, increasing the number of crops per year from one or two to two, three, or even more. Dike infrastructures have been built and intensified after 2000 to block the flood way into the fields during the flood season so as to allow an additional crop cycle. Short-cycle rice varieties (80-100 days) are planted in order to harvest three crops per year instead of one or two. Finally, modern water management has been partly introduced in the last three years, consisting in intermittent drainage between two irrigation operations.

For those changes in cultural practices, the intensity temporal change method for rice mapping and monitoring needs to be upgraded. In this paper, a method using polarization information is developed and assessed for this purpose.

Because of the vertical structure of rice plants, the difference between $\mathrm{HH}$ and VV backscattering is expected to be higher than that of other crop or land cover types, and through the relation with wave attenuation in the canopy, the ratio of the $\mathrm{HH}$ and VV backscattering coefficients (hereafter called HH/VV) can be related to the vegetation biomass. A joint analysis of ERS and RADARSAT-1 data [7], [10], and the modeling of C-band $\mathrm{HH}$ and VV [7], [8] revealed that $\mathrm{HH}$ is significantly higher than $\mathrm{VV}$, and the difference can reach 6-7 dB at the peak growth stage. Based on these findings, $\mathrm{HH} / \mathrm{VV}$ is potentially a good classifier for rice monitoring, and methods using $\mathrm{HH} / \mathrm{VV}$ need to be developed and assessed.

Specifically, in this paper, the method is developed using a time series of dual polarization ( $\mathrm{HH}$ and VV) ASAR data and tested in the province of An Giang in the Mekong Delta. Section II describes the test site and data used in the study. The use of HH/VV as a rice classifier requires a prior statistical study of this polarization ratio on rice and non-rice pixels at different dates, which is reported in Section III. Section IV presents the implementation of the newly developed mapping algorithms, followed by mapping results and validation.

\section{SITE AND DATA}

\section{A. Site Description}

The study site is in the Mekong Delta, South Vietnam. This region accounts for more than half of the rice production in Vietnam, the fifth producer country in the world with about $6 \%$ of the global production in 2007 [2]. Vietnam is second to Thailand in rice export, and $80 \%-85 \%$ of the rice exported from Vietnam stems from the Mekong Delta.

The Mekong Delta lies in latitude from $8.5^{\circ}$ to $11^{\circ} \mathrm{N}$ and is a wide $\left(40000 \mathrm{~km}^{2}\right)$ flat plain of sedimentation at the mouth of the Mekong and Bassac rivers. Seasonal changes in the precipitation are caused by the monsoon and divide the year 
into dry season, running from December to late May, early June, and wet season, from June to November, with $1600-2000 \mathrm{~mm}$ of rain annually. At the end of the rainy season, the Mekong and Bassac rivers overflow their banks in the northern part of the delta, resulting in flood that affects one third of the delta.

During the wet season, there are two rice cropping patterns, depending on the ecosystem (irrigated or rainfed). In the irrigated areas, the farmers produce both a "Summer-Autumn" and an "Autumn-Winter" rice crop, with high yield varieties. The Summer-Autumn or early rainy season rice crop (locally named "He Thu") is planted in April-early June and harvested in July-early August. The Autumn-Winter or late rainy season (locally named "Thu Dong") is transplanted in August and harvested in November-December. In the rainfed areas, the farmers produce the "main wet season" crop (locally named "Mua"). This is a rainfed crop planted with traditional varieties in July-August. They have various growing durations: early (harvested in late October-early November), medium (harvested in late November-December), and late (harvested in January-February). During the dry season, in the irrigated areas, the farmers grow "Winter-Spring" or dry season crop (locally named "Dong Xuan"). It is planted in November-December and harvested in February-April. However, locally, the crop calendar varies each year, depending on the onset of the rainy season for the start of the Summer-Autumn crop, on the duration of the flood and the date of the Spring festival which occurs in January-February.

A system of canals and dikes to bring irrigation water and control floodwater is being developed to complement the existing system that operated mainly as an irrigation source. Farmers construct minor canals and dikes to control water in their fields. During the dry season, electric pumping is used when water cannot reach the fields through canals.

Special attention is paid to the An Giang province. This province covers an area of $3406 \mathrm{~km}^{2}$. The land use is dominated by agricultural land $(79.5 \%)$, comprising mostly rice farms (94\%, thus $75 \%$ of total area) [22].

\section{B. SAR Data}

Time series of ASAR images have been acquired during the year 2007. The ASAR instrument is a C-band SAR $(5.6-\mathrm{cm}$ wavelength) on board ENVISAT and operating in a number of modes: fine beam with various combinations of incidence and polarization, and ScanSAR. This study uses the fine-beam dual-polarization alternating polarization precision (APP) data (APP image) with incidence IS2 $\left(19.2^{\circ}-26.7^{\circ}\right)$ in $\mathrm{HH}$ and VV polarization. APP images have a nominal spatial resolution of $30 \times 30 \mathrm{~m}$ and pixel size of $12.5 \times 12.5 \mathrm{~m}$, with a swath width of about $100 \mathrm{~km}$. The exact revisit cycle of ENVISAT is 35 days.

To cover the whole An Giang province, two parallel satellite tracks in ascending pass have been used. Eight images are available in 2007 over the western track (February 1, March 8, April 12, May 17, June 21, July 26, August 30, and October 4) and ten over the eastern track (January 13, February 17,

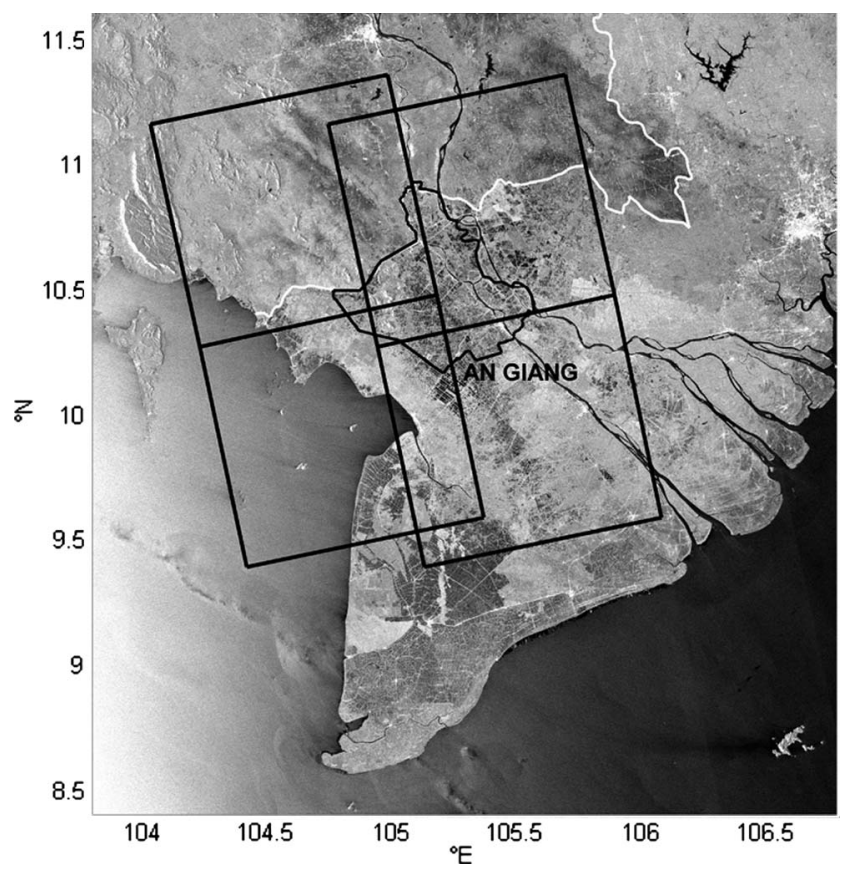

Fig. 1. Location of An Giang province in the Mekong Delta on an ENVISAT ASAR ScanSAR wide swath mode image of South Vietnam. In white is the Vietnam-Cambodia border. Frames are those of ASAR APP data used in this study.

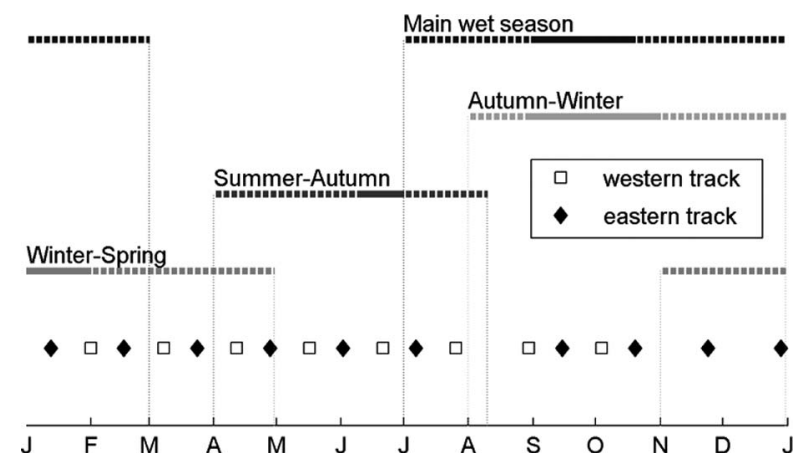

Fig. 2. Rice calendar in the province of An Giang in the Mekong Delta and dates of the available ASAR APP data. For each rice crop, dashed lines represent the periods during which the beginning and end of the crop can take place (spatial and interannual variability).

March 24, April 28, June 2, July 7, September 15, October 20, November 24, and December 29).

Fig. 1 shows the location of the province of An Giang and the ASAR APP frames under study. Fig. 2 shows the calendar of the main rice crops and the dates of available ASAR data.

\section{Ground Data}

A geographic information system (GIS) land cover database covering the Cho Moi district in An Giang province, which was completed in 2005, is provided by the University of An Giang. The land is classified and subclassified into forests, water bodies (rivers and lakes), nonvegetation cover, agricultural land (rice, mixed rice and vegetables, annual plants, and perennial trees), residential areas (urban and suburban), and others. 


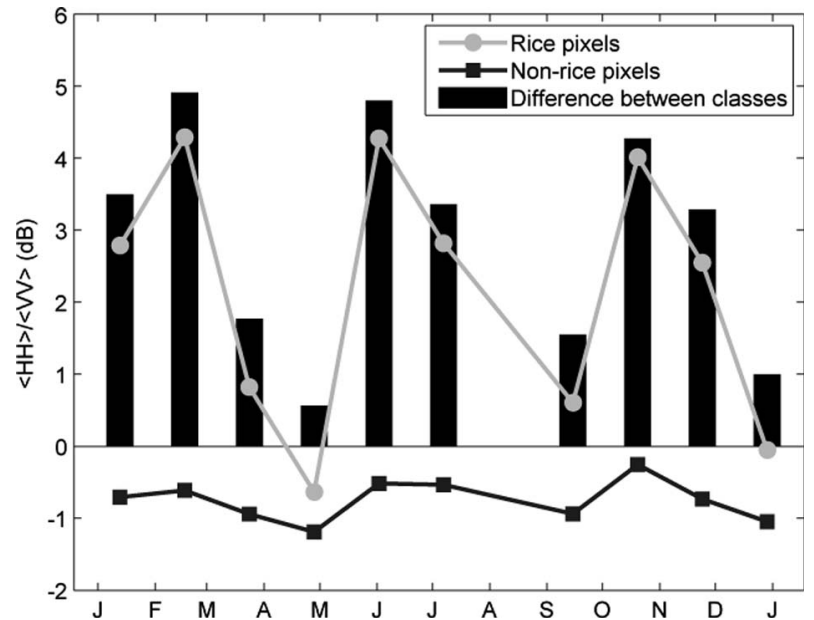

Fig. 3. Polarization ratio of the mean intensities $\langle\mathrm{HH}\rangle /\langle\mathrm{VV}\rangle$ for pixels defined as (gray circles) rice and (black square) non-rice in the GIS database. Black bars represent the difference of this ratio between the two classes.

\section{Development of Rice Mapping Methodology BASED ON THE POLARIZATION RATIO HH/VV}

\section{A. Approach}

The methodology development will be based on results of analysis carried out at the test area in the Cho Moi district. APP images of the eastern track are analyzed regarding the $\mathrm{HH} / \mathrm{VV}$ ratio of rice and non-rice classes, with the help of the GIS database. The results will be used in Section IV to derive rice mapping algorithms that will be applied to the APP data from the two tracks to map the whole An Giang province.

\section{B. Analysis}

1) Data Preprocessing: The APP level 1 images are preprocessed using the Gamma GEO software (Gamma Remote Sensing, Switzerland). This preprocessing comprises the following steps:

1) creation of a precision image for each polarization of each APP image;

2) conversion into backscattering coefficients $\left(\sigma^{0}\right)$ from digital numbers using a calibration factor, following the procedure specified by the European Space Agency (ESA) [23];

3) geocoding.

For this very flat terrain in the whole Mekong Delta, no Digital Elevation Model is needed to perform an accurate geocoding.

The GIS database is superimposed to the geocoded ASAR images and rasterized to create masks of rice and non-rice pixels. For this region of 31000 ha, the rice mask contains more than 1380000 pixels (about $21000 \mathrm{ha}$ ) and the non-rice mask contains 632000 pixels (about 10000 ha).

2) Statistical Analysis: A statistical study is conducted on the rice and non-rice pixels identified using the GIS.

Fig. 3 shows the ratio of the mean $\mathrm{HH}$ and $\mathrm{VV}$ values $\langle\mathrm{HH}\rangle /\langle\mathrm{VV}\rangle$ for these two classes at the ten dates under study (conversion to decibels is done only after averaging and ra- tioing). The non-rice class exhibits $\langle\mathrm{HH}\rangle /\langle\mathrm{VV}\rangle$ values around $-0.75 \mathrm{~dB}( \pm 0.5 \mathrm{~dB})$ at all dates, whereas the rice class shows variations as a function of growth stage during each of the three crop seasons. Maximum values of $4.3 \mathrm{~dB}$ are found at the peak growth stages. Fig. 3 also shows the difference in decibels between the $\langle\mathrm{HH}\rangle /\langle\mathrm{VV}\rangle$ values of the two classes and indicates a high class separability (difference higher than $3 \mathrm{~dB}$ ) at two dates per season (January 13 and February 17 for the Winter-Spring season, June 2 and July 7 for the Summer-Autumn season, and October 20 and November 24 for the Autumn-Winter season). Note that, for the Autumn-Winter season, only one part (about $75 \%$ in Cho Moi) of GIS rice pixels are grown as rice; therefore, about $25 \%$ of the pixels in the rice class are actually not rice, resulting in an underestimation of the $\langle\mathrm{HH}\rangle /\langle\mathrm{VV}\rangle$ of the true rice class.

Thus, mapping rice with a threshold on $\mathrm{HH} / \mathrm{VV}$ at a single date appears possible at six of the ten dates. Using GIS, fieldbased classification methods could be developed and assessed. However, for a more general use when updated GIS data are not available, pixel-based classification is considered. For this purpose, relevant speckle filtering needs to be applied, considering that the $\mathrm{HH} / \mathrm{VV}$ distributions of rice and non-rice could be largely overlapping, even if their mean values are significantly different.

The statistical framework of such a mapping method is similar to that of the temporal change detection method developed in [24], using a threshold on the ratio of backscatter intensities at two dates for the latter and at two polarizations for the former.

Under the assumption of gamma distributed multilook SAR intensities, the probability density function (pdf) of the intensity ratio $r=\mathrm{HH} / \mathrm{VV}$ of a homogeneous region is found to depend only on the ratio of average intensities $\bar{r}=\langle\mathrm{HH}\rangle /\langle\mathrm{VV}\rangle$ and not directly on the average intensities $\langle\mathrm{HH}\rangle$ and $\langle\mathrm{VV}\rangle$

$$
p(r \mid\langle H H\rangle,\langle V V\rangle)=\frac{(2 L-1) !}{(L-1) !^{2}} \frac{\bar{r}^{L} r^{L-1}}{(\bar{r}+r)^{2 L}}
$$

where $L$ is the number of looks.

We use a threshold $r_{t}$ to decide on whether to classify a pixel having a given polarization ratio $r$ into class $\mathrm{A}$, characterized by a polarization ratio $r_{A}=\left\langle\mathrm{HH}_{A}\right\rangle /\left\langle\mathrm{VV}_{A}\right\rangle$, or class $\mathrm{B}$, characterized by a polarization ratio $r_{B}=\left\langle\mathrm{HH}_{B}\right\rangle /\left\langle\mathrm{VV}_{B}\right\rangle$. With $r_{B}>r_{A}, r \geq r_{t}$ is classified as class $\mathrm{B}$ and $r<r_{t}$ as class $\mathrm{A}$. Fig. 3 shows that class B should be rice and class A non-rice.

Assuming equal a priori probabilities for both classes $(p(A)=p(B))$, the optimal threshold $r_{0}$ is found for $p\left(r_{0} \mid r_{A}\right)=p\left(r_{0} \mid r_{B}\right)$, leading to

$$
r_{0}=\sqrt{r_{A} r_{B}}
$$

In the general case of unknown a priori probabilities, we find that the probability of error in the classification with a threshold $r_{t}=d \cdot r_{0}$ is

$$
P E=(1-p(B)) \cdot h(d \cdot X)+p(B) \cdot h\left(\frac{X}{d}\right)
$$




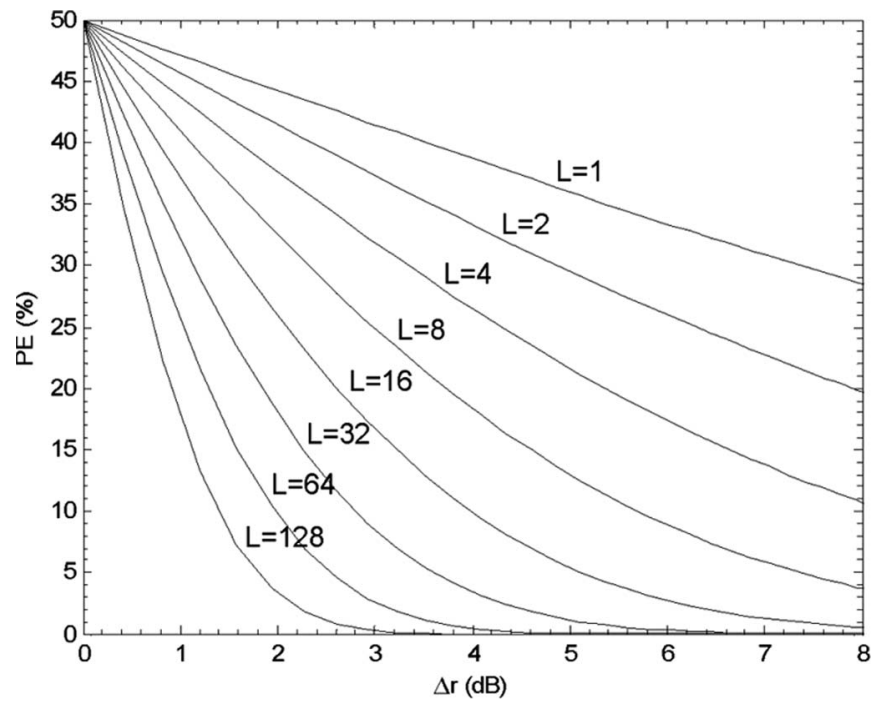

Fig. 4. Probability of error (in percent) of the ratio method versus the change in polarization ratio $\Delta r$ (in decibels) between the two classes, for a number of looks $L$ varying between 1 and 128 .

where

$$
h(X)=\frac{(2 L-1) !}{(L-1) !^{2}} \sum_{j=0}^{L-1} \frac{(L-1) !}{j !(L-j-1) !} \frac{(-1)^{j}}{L+j} \frac{1}{(1+X)^{L+j}}
$$

and $X=\sqrt{r_{B} / r_{A}}$.

A numerical analysis based on (3) shows that, for the general case, the optimal classification threshold depends on $r_{0}, L, X$, and the a priori probability of rice $p(B)$. However, for cases likely to be encountered $(\mathrm{X} \geq 1.5, \mathrm{~L} \geq 6$, and $\mathrm{p}(\mathrm{B}) \leq 0.8)$, using $r_{0}$ instead of the true optimal threshold leads to only slightly suboptimal results (less than 5\% of additional error in the worst case).

The expression of the probability of error with $r_{0}$ as a classification threshold $(d=1)$ reduces to

$$
P E=h(X) .
$$

Fig. 4 shows the probability of error PE versus the difference between the mean ratios of the two classes $\Delta r=r_{B} / r_{A}=X^{2}$, for different values of $L$, when the classification threshold is $r_{0}$.

In order to study the statistical distributions of the HH/VV polarization ratio for the two classes and to determine the $r_{A}$ and $r_{B}$ values necessary to implement the mapping method, we compute the ratio between $\mathrm{HH}$ and VV ASAR backscattering images (values in linear scale, not logarithmic scale) on a pixel basis, to create an HH/VV image at each date. In this study, all pixels for each class are taken into account in the calculations of mean values or histograms.

Fig. 5(a) shows examples of HH/VV normalized histograms of rice and non-rice pixels at the three dates during the Summer-Autumn season. The values of $r_{A}$ and $r_{B}$ are derived from Fig. 3; $r_{0}$ and $\Delta r$ are calculated consequently. The first date was in the early stage of the rice season, where very similar distributions of the $\mathrm{HH} / \mathrm{VV}$ of rice and non-rice pixels are observed. The second and third dates correspond to well- developed stages (booting to flowering). The two distributions have significant differences in their mean values. However, they are also largely overlapped. For rice/non-rice classification, the variance of the distributions of the pixel-based $\mathrm{HH} / \mathrm{VV}$ needs to be reduced. This is achieved by speckle filtering that will result in an increase in the number of looks of each pixel.

Fig. 4 can be used to estimate the number of looks required in the pixel-based classification. The ASAR APP data at incidence IS2 have a number of looks equal to 1.4. With $\Delta r$ equal to $4.7 \mathrm{~dB}$ (at the date of June 2), the probability of error PE should be around $35 \%$. To decrease the probability of error to $10 \%$, the equivalent number of looks (ENL) should rise to around 12 . Likewise, if $\Delta r=3.5 \mathrm{~dB}$, ENL is around 20.

3) Multichannel Filtering: A multichannel filter described in [25] was developed to reduce the speckle noise in SAR images and thus increase the original number of looks in the image to a higher ENL, without reducing the spatial resolution. The filter linearly combines $M$ input images on a pixel-topixel basis, to create $M$ output images with reduced speckle. For uncorrelated images with the same number of looks $L$, the linear combination is

$$
J_{k}(x, y)=\frac{\left\langle I_{k}(x, y)\right\rangle}{M} \sum_{i=1}^{M} \frac{I_{i}(x, y)}{\left\langle I_{i}(x, y)\right\rangle}
$$

where

$J_{k}(x, y) \quad$ radar intensity of output image $k$ at pixel $(x, y)$;

$I_{i}(x, y) \quad$ radar intensity of input image $i$ at pixel $(x, y)$;

$\left\langle I_{i}(x, y)\right\rangle$ local average intensity of input image $i$ at pixel $(x, y)$.

The local average intensity is calculated using an averaging window of $N$ pixels.

The theoretical value of the ENL of the output filtered images is

$$
E N L=\frac{M \times N \times L}{M+N-1} .
$$

With $M=20$ images (ten dates and two polarizations) of $L=1.4$ look, we calculate from (7) that the requested ENL of 12 requires an averaging window $(N)$ of at least 14 pixels. A $5 \times 5$ square window ( 25 pixels) is chosen in this study for the multichannel filtering, resulting in an ENL of 15.9.

Similarly, if the requested ENL is $20, N=46$, and the window size is $7 \times 7$.

4) Statistical Analysis After Filtering of the ASAR Images: Fig. 5(b) shows the same histograms of rice and non-rice pixels as in Fig. 5(a), but after filtering. The separability of the two classes for the fully grown stages is improved significantly. In particular, it is to be noted that the filtering can reveal rice pixels with different calendars, as in the result of the last date, where a part of the rice fields have been harvested, resulting in a bimodal histogram. As a consequence, the values of $r_{B}$ have been calculated on an area with a nonnegligible proportion of non-rice pixels and must be re-estimated. To do so, we consider that, since the two modes of the bimodal histograms are relatively well separated, the theoretical pdf given in (1) and the rice mode in the histogram have their maxima at the same 

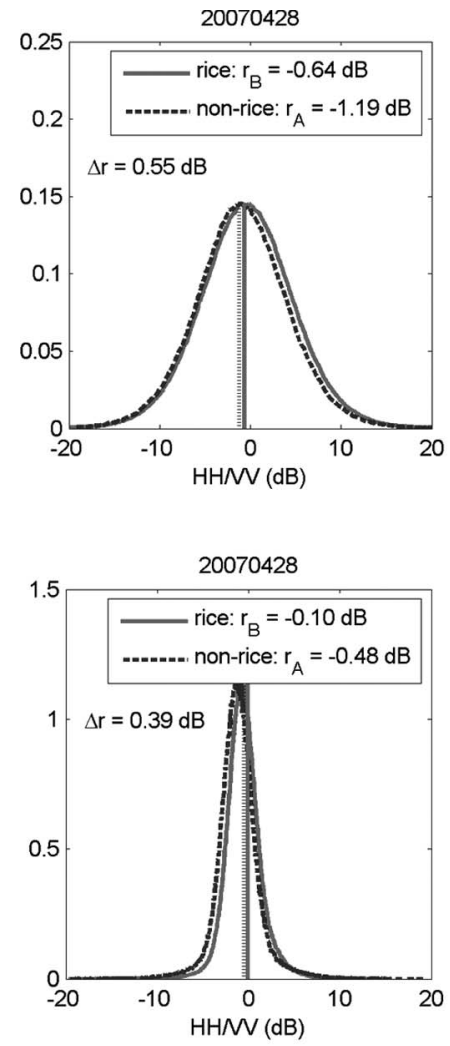

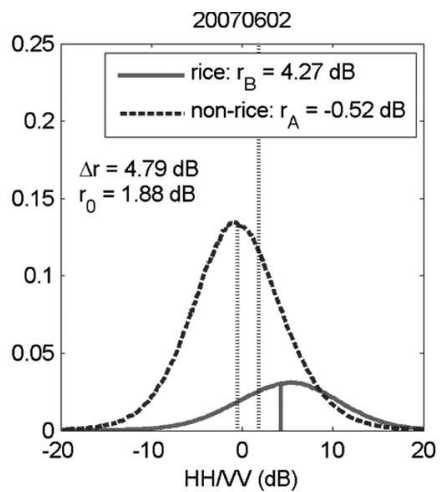

(a)

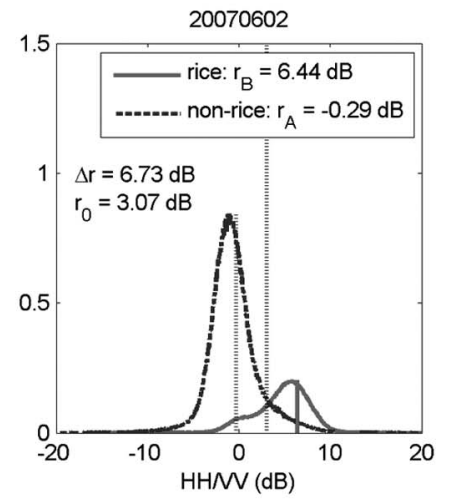

(b)
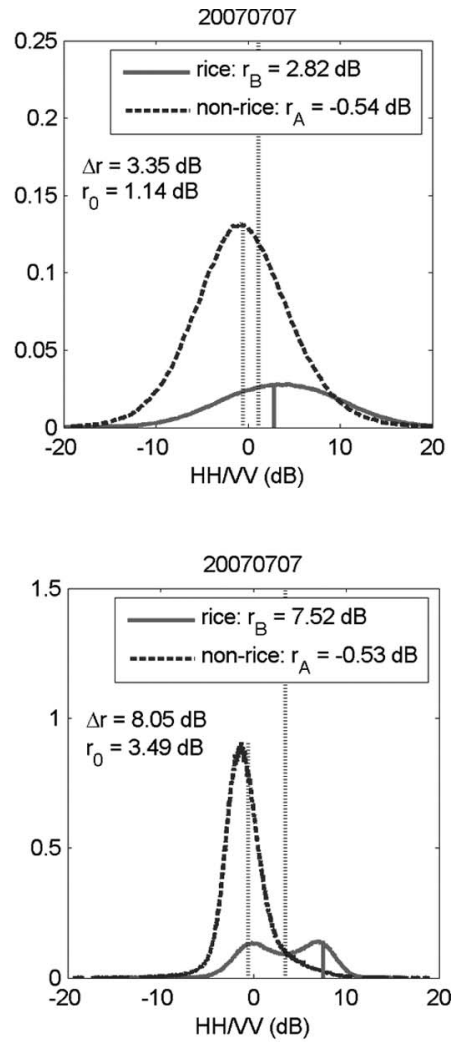

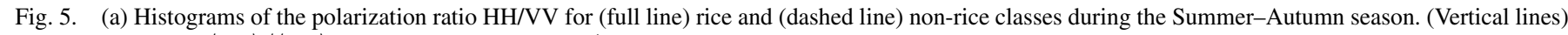

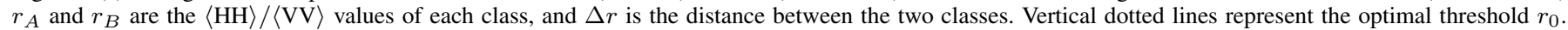

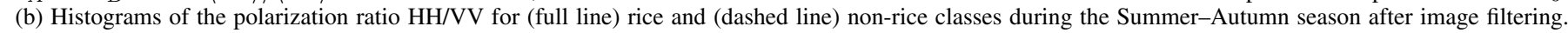

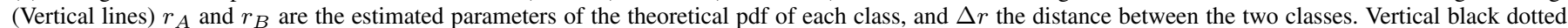
lines represent the optimal threshold $r_{0}$.

polarization ratio value $r_{\max }$. Furthermore, $r_{\max }$ is analytically found from (1) to be directly related to $r_{B}$

$$
r_{\max }=\frac{L-1}{L+1} r_{B}
$$

where $L$ is the ENL (15.9 here). $r_{B}$ and $r_{A}$ are thus estimated at each date by retrieving $r_{\max }$ from the rice and non-rice histograms, respectively, and using (8). The newly estimated values of $r_{A}, r_{B}, r_{0}$, and $\Delta r$ for the three dates of the Summer-Autumn season are shown in Fig. 5(b), and Fig. 6 shows the values of $r_{A}, r_{B}$, and $\Delta r$ for the ten images available in the three rice seasons in 2007, as well as the previously estimated values from Fig. 3 for comparison. The new values exhibit a higher class separability, with $\Delta r$ higher than $5 \mathrm{~dB}$ at two dates per season and reaching a maximum of $8 \mathrm{~dB}$. The corresponding values of $r_{0}$ range from 2.0 to $3.5 \mathrm{~dB}$, with a mean value around $3 \mathrm{~dB}$.

\section{Implementation of Rice Mapping Algorithms}

\section{A. Principles}

The rice mapping methods are tested on the 2007 Summer-Autumn rice season. The test is performed on singleand multidate data sets.

The single-date mapping method relies on the use of a threshold on the polarization ratio using the optimal threshold

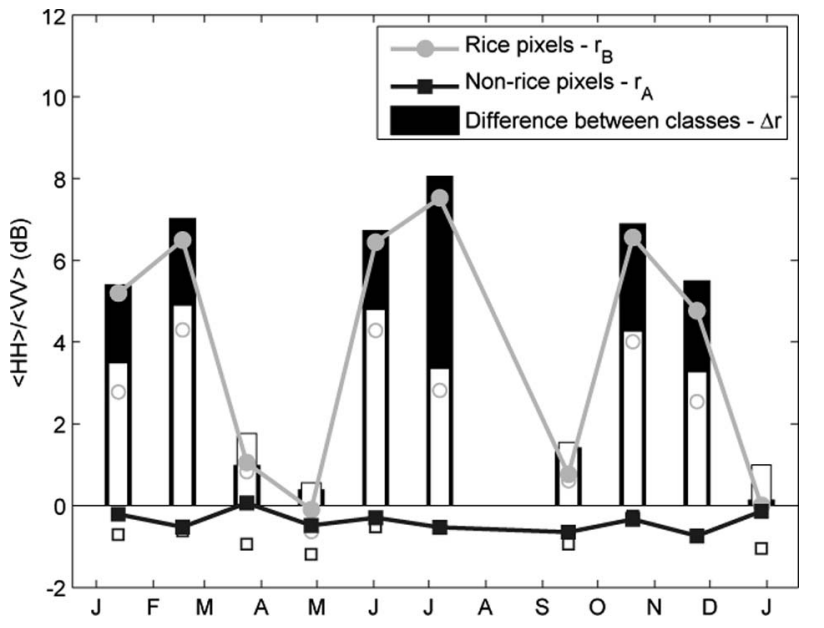

Fig. 6. Estimated values of $r_{A}$ and $r_{B}$ for (gray circles) rice and (black squares) non-rice classes in 2007, and $\Delta r$ is in black. Empty symbols and bars represent the previously estimated values from Fig. 3.

given in (2). For the Summer-Autumn season, with the APP image from June 2, a pixel is classified as rice when its polarization ratio is higher than $r_{0}=3.07 \mathrm{~dB}$ and classified as non-rice if otherwise. To remove noise in the rice maps induced by remaining speckle effects or filtering artifacts, the clusters detected as rice with a size of less than 100 pixels (about $1.4 \mathrm{ha}$ ) are removed from the rice class. This is based on the fact 

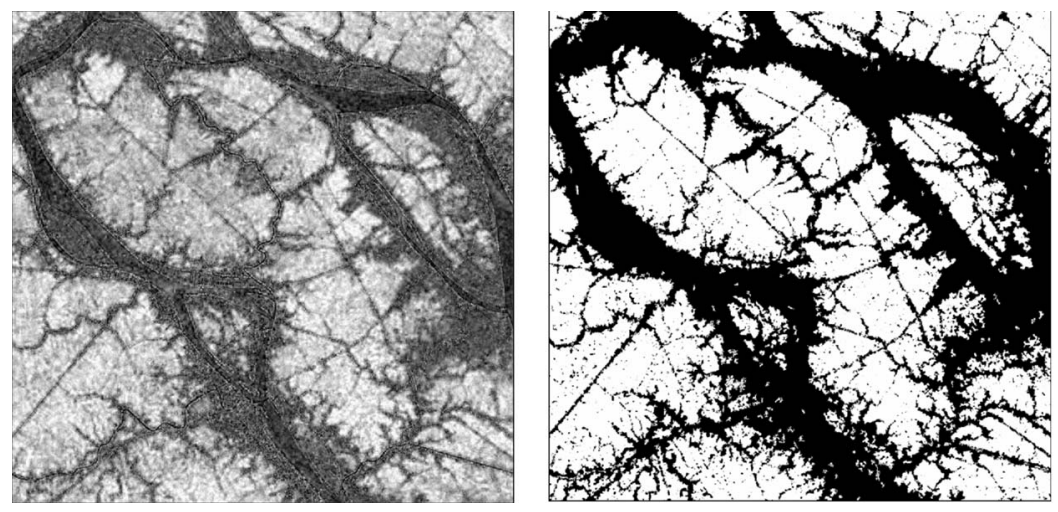

Fig. 7. (Left) Polarization ratio image of the filtered ASAR data on June 2 in the Cho Moi district and (right) derived Summer-Autumn rice map using the multidate method, white pixels $=$ rice.
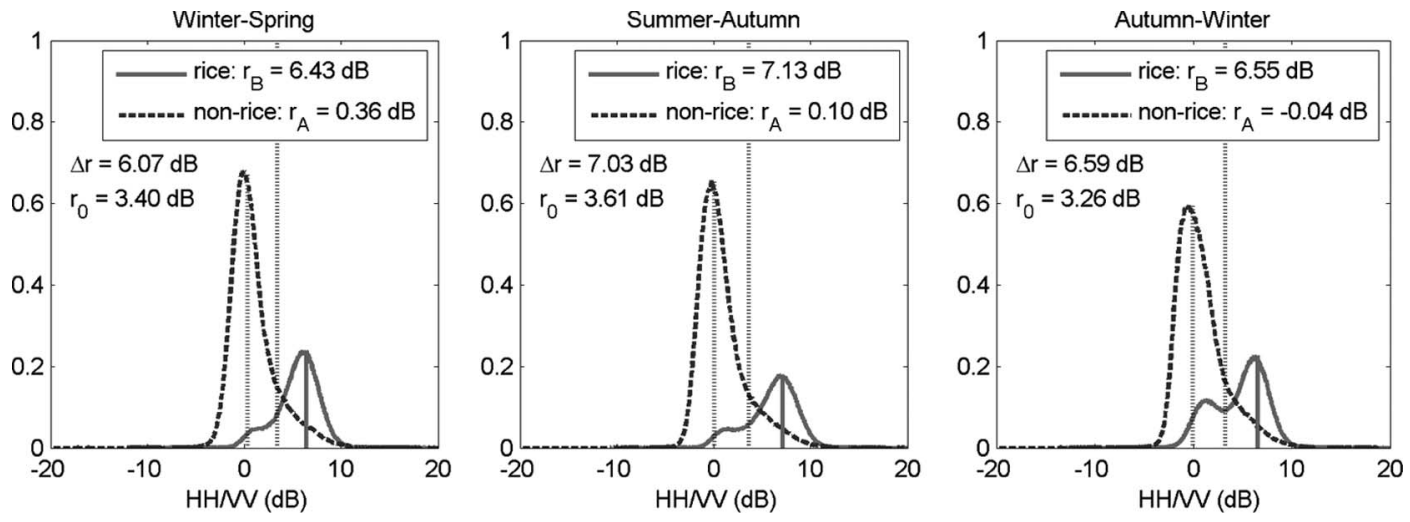

Fig. 8. Histograms of the maximum polarization ratio HH/VV of the (full line) rice and (dashed line) non-rice classes during (left) the Winter-Spring season, (middle) the Summer-Autumn season, and (right) the Autumn-Winter season in 2007, after image filtering, in the Cho Moi district.

that, in the Mekong Delta, rice cultivation is often organized by cooperatives of several farmers' owned fields. Rice fields, even of small size, are usually regrouped in large units.

The single-date method is expected to provide early mapping results. However, the rice fields in a same area can have a slightly shifted calendar. In the previous case (single-date mapping on June 2), later sown fields may have a higher polarization ratio on the next acquired date (July 7) and may be best detected at this date, when earlier sown fields are already harvested. This constitutes a potential source of omission error (rice classified as non-rice) in the single-date method. Comparatively, commission error (non-rice classified as rice) is expected to be much lower than omission error. The overall error can thus be reduced if the classification is applied to all available dates when $\Delta r$ is higher than $4 \mathrm{~dB}$ (here, two dates per season). In this multidate method, a pixel is assigned to rice class if it is classified as rice (according to the single-date method) for at least one of the dates.

Fig. 7 shows the June 2 image and the multidate rice map derived from the three images acquired during the SummerAutumn season.

For the general case when no GIS data are available, the optimal thresholds $r_{0}$ and the difference between classes $\Delta r$ at each date cannot be calculated, and the mapping method cannot be applied exactly as described previously. Therefore, there is a need to define a default threshold suitable for rice mapping at any date. With a constant default threshold, the multidate method consists of the union of the rice maps obtained by the single-date method at each available date within the season and is therefore strictly equivalent to applying this threshold on the maximum value of $\mathrm{HH} / \mathrm{VV}$ in all the available dates for each pixel. The histograms of the maximum value of $\mathrm{HH} / \mathrm{VV}$ of rice and non-rice at the three seasons for each pixel are shown in Fig. 8 and indicate a default threshold around $3 \mathrm{~dB}$, which is consistent with the $r_{0}$ values found previously.

This method can be used sequentially to provide results early in the season that can be improved in near-real time at each further data acquisition during the season.

\section{B. Validation and Discussion}

The results of these methods are assessed using the rice and non-rice masks derived from the GIS data. To reduce errors due to the possible position shift between the geocoding of the ASAR data and that of the GIS, and potential inaccuracies in the GIS polygon delineation, each polygon of the GIS is eroded $(3 \times 3 \mathrm{kernel})$ to take into account only validation pixels that have higher reliability. The GIS gives information on the spatial distribution of rice fields, but not on the cropping systems. A field labeled as rice can be grown at one, two, or three of the rice seasons. Therefore, to allow comparison between the GIS data and ASAR results, the yearly spatial distribution of rice is derived from the rice maps obtained by the single- or multidate methods at the three seasons. This spatial distribution consists in the collection of the pixels that are detected as rice during at least one of the three seasons. 


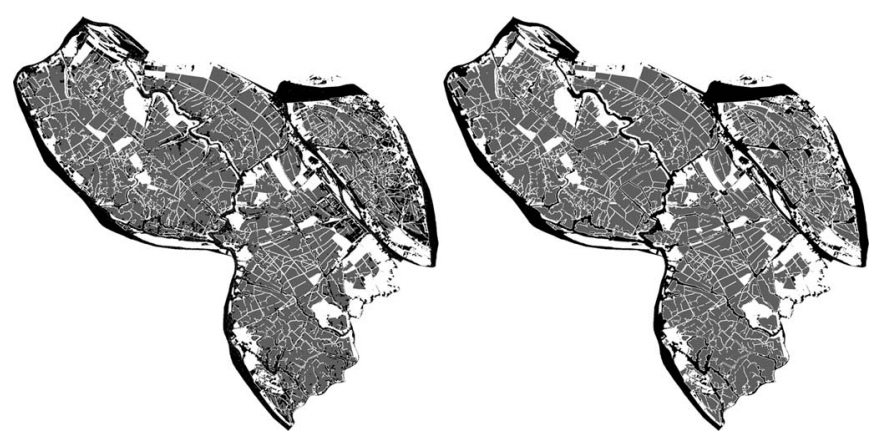

Fig. 9. (Left) Yearly spatial distribution of rice fields derived by ASAR, and (right) land use reported by the GIS, where rice appears in gray, non-rice in black, and pixels not included in the GIS in white.

TABLE I

Sown Area in the Cho Moi District in 2007 for Each Season and Total Sown Area Retrieved by the Single- And Multidate Methods

\begin{tabular}{ccccc}
\hline \hline & Total & Winter-Spring & Summer-Autumn & Autumn-Winter \\
\hline Single-date method & $45336 \mathrm{ha}$ & $15952 \mathrm{ha}$ & $16015 \mathrm{ha}$ & $13369 \mathrm{ha}$ \\
Multi-date method & $49909 \mathrm{ha}$ & $17825 \mathrm{ha}$ & $17855 \mathrm{ha}$ & $14228 \mathrm{ha}$ \\
$\%$ Difference & $+9,2 \%$ & $+10,5 \%$ & $+10,3 \%$ & $+6,0 \%$ \\
\hline \hline
\end{tabular}

The comparison between rasterized GIS pixels and the rice spatial distribution derived from ASAR in Fig. 9 shows a pixel-based agreement of $89.9 \%$ (commission rate $=2.8 \%$, omission rate $=7.3 \%$, with respect to rice) for the multidate method and $85.6 \%$ (commission rate $=2.2 \%$, omission rate $=$ $12.2 \%$, with respect to rice) for the single-date method. Several causes can be the sources of disagreement: 1) changes in land use between 2005 (GIS) and 2007 (ASAR); 2) the position shift between ASAR and GIS; 3) initial errors in the GIS; and 4) error attributable to the ASAR method. Despite the error sources, $90 \%$ of agreement is a promising result.

These results confirm that the multidate method reduces omission error without increasing much commission error, compared to the single-date method.

The improvement induced by the multidate method (using all dates available within a season) over the single-date method (using the optimal date within a season) can also be assessed by comparing the sown areas retrieved by the two methods for each season, given in Table I, to the sown areas given in official statistics. The Agriculture and Rural Development Department of the An Giang province, which provides yearly statistics of rice sown area, has published the statistics for the first season in 2007 (Winter-Spring). The value of 17886 ha for the Cho Moi district is in very good agreement with the multidate SAR-based results (17825 ha), while the single-date results underestimate the sown area by $11 \%$ (15952 ha). The figures for the two last seasons will be published during 2008 .

\section{Extension to the Whole Province}

The method is applied on images of the two tracks to map rice crops in the An Giang province.

To map rice area for the four rice seasons (Winter-Spring, Summer-Autumn, Autumn-Winter, and main wet season), the multidate method with a constant threshold at $3 \mathrm{~dB}$ was applied as follows:

1) Winter-Spring using six dates: February 1 , March 8 , and April 12 (western track), and January 13, February 17, and March 24 (eastern track);

2) Summer-Autumn using six dates: May 17, June 21, and July 26 (western track), and April 28, June 2, and July 7 (eastern track);

3) Autumn-Winter and main wet season together using five dates: August 30 and October 4 (western track), and September 15, October 20, and November 24 (eastern track).

Autumn-Winter and main wet season rice were then separated by considering that main wet season rice was grown only as a single crop (i.e., no rice at the two other seasons).

Fig. 10 shows the results where rice crops at all seasons are distinguished.

The estimated planted areas for the An Giang province are the following: 224273 ha in the Winter-Spring season, 222746 ha in the Summer-Autumn season, 72070 ha in the Autumn-Winter, and 4973 ha in the main wet season, which make a total of 524061 ha of rice planted in 2007.

The Agriculture and Rural Development Department of the An Giang province publishes a Winter-Spring sown area of 229694 ha for the An Giang province. The figures for the two last seasons will be published during 2008 .

The General Statistics Office of Vietnam reports the paddy rice planted areas for each province in the country [26] divided into three categories: Spring, Autumn, and Winter paddies. After an examination of these statistics, it appears that Spring paddy corresponds to the Winter-Spring season, Autumn paddy to the sum of Summer-Autumn and Autumn-Winter seasons, and Winter paddy to the main wet season.

Fig. 11 shows the evolution of the planted areas of rice in the recent past years (1995-2006) together with the 2007 area as assessed by ASAR. 


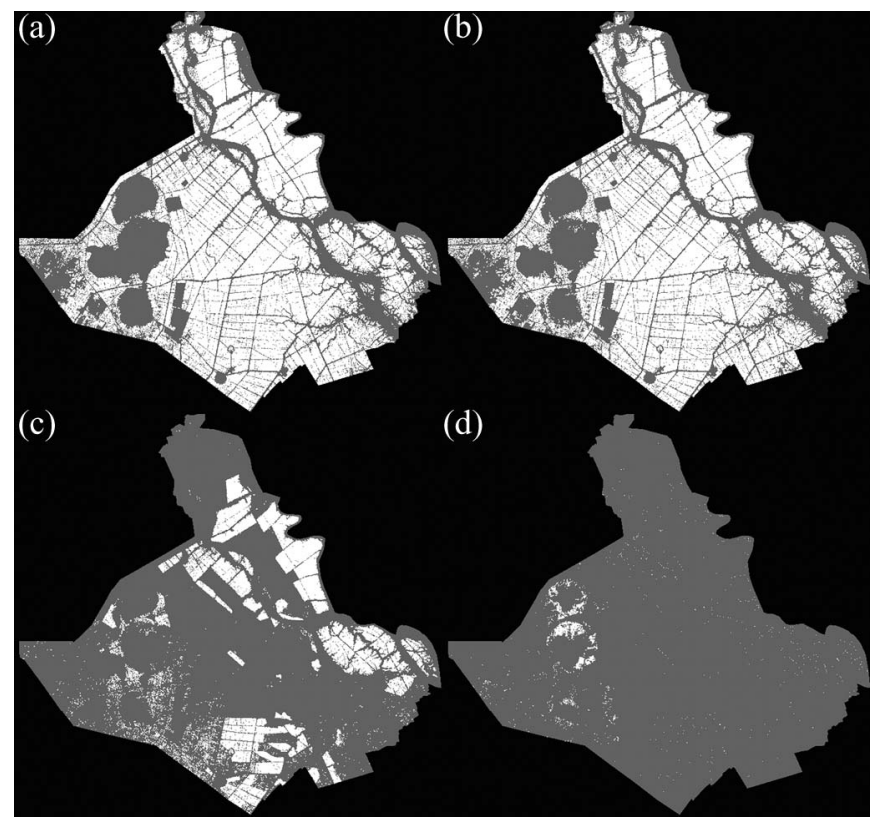

Fig. 10. Rice maps of the An Giang province derived from the multidate method for (a) Winter-Spring, (b) Summer-Autumn, (c) Autumn-Winter, and (d) main wet season in 2007 (white is rice, gray is non-rice, and black is outside An Giang province).

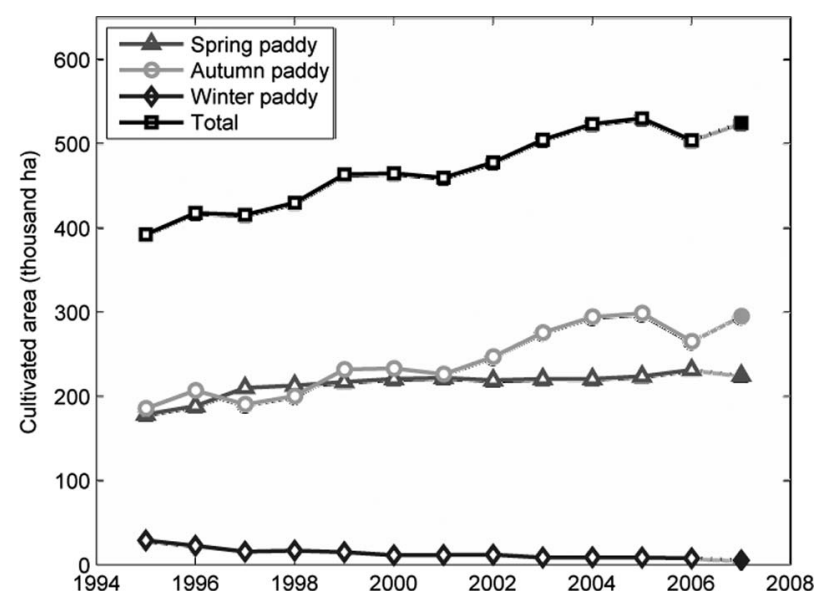

Fig. 11. Cultivated area of paddy rice in the An Giang province as reported by the General Statistics Office of Vietnam (1995-2006) and derived from the retrieved rice maps (2007).

In general, there is an increase in area for the main seasons: Spring and Autumn paddy (and a decrease in Winter paddy). The total rice grown area increases of about 35\% from 1995 to 2005. The increase is particularly significant for the Autumn paddy since 2002. It can be understood that, after the big floods in years 1999-2000, the dike network was intensified to protect the region from floodwater. As a consequence, Autumn-Winter rice could be grown in places where it was not possible before. The increase in Autumn rice is diminished in 2006 when less rice has been planted to avoid the propagation of a disease inoculated by brown planthoppers that occurred since the end of 2005. According to our results, the 2007 Autumn rice is back to the level of 2005. Of course, this needs to be further verified.

\section{CONCLUSION}

Methods for rice field mapping based on the use of the polarization ratio $\mathrm{HH} / \mathrm{VV}$ of ASAR APP data at a single date or at multiple dates (maximum of three in the same satellite track) have been developed and validated at a test area in the Mekong Delta, Vietnam, with a pixel-based agreement with local (district) GIS information of around $90 \%$.

The results obtained for the rice season have been compared to the statistics of the province of An Giang. The SAR method has provided the quasi-exact values published in February 2007 for the planted area of the first rice season in 2007. This promising result shows that methods using SAR data can be timely and cost effective.

The method is well-suited to regions where fields have multiple crops and shifted calendars. $\mathrm{HH} / \mathrm{VV}$ is expected to remain high even for drained fields; this has to be further studied. A default threshold on the HH/VV values was defined to make the method more general. Therefore, this mapping method is expected to be operational with the advanced satellite SAR systems at C-band providing $\mathrm{HH}$ and $\mathrm{VV}$ data together, such as ASAR and RADARSAT-2.

Further works will consist of an improvement of the method by using $\mathrm{HH} / \mathrm{VV}$ and the temporal change of $\mathrm{HH}$ and/or VV in the multidate approach. The method will be tested for rice mapping in the entire Mekong Delta, using both ENVISAT APP and Wide Swath (ScanSAR) data.

\section{ACKNOWLEDGMENT}

The ENVISAT/ASAR data used in this study were provided by ESA (Cat-1 AO Project 697).

\section{REFERENCES}

[1] IRRI, January 2008 Press Release. [Online]. Available: http://www. irri.org/media/press/press.asp?id $=168$

[2] FAO, FAOSTAT (Food and Agriculture Organization). [Online]. Available: http://faostat.fao.org/site/567/default.aspx

[3] X. Xiao, S. Boles, S. Frolking, W. Salas, B. Moore, III, and C. Li, "Observation of flooding and rice transplanting of paddy rice fields at the site 
to landscape scales in China using VEGETATION sensor data," Int. J. Remote Sens., vol. 23, no. 15, pp. 3009-3022, Aug. 2002.

[4] X. Xiao, S. Boles, J. Liu, D. Zhuang, S. Frolking, C. Li, W. Salas, and B. Moore, III, "Mapping paddy rice agriculture in southern China using multi-temporal MODIS images," Remote Sens. Environ., vol. 95, no. 4, pp. 480-492, Apr. 2005.

[5] X. Xiao, S. Boles, S. Frolking, C. Li, J. Y. Babu, W. Salas, and B. Moore, III, "Mapping paddy rice agriculture in South and Southeast Asia using multi-temporal MODIS images," Remote Sens. Environ., vol. 100, no. 1, pp. 95-113, Jan. 2006.

[6] T. Sakamoto, N. V. Nguyen, H. Ohno, N. Ishitsuka, and M. Yokozawa, "Spatio-temporal distribution of rice phenology and cropping systems in the Mekong Delta with special reference to the seasonal water flow of the Mekong and Bassac rivers," Remote Sens. Environ., vol. 100, no. 1, pp. 1-16, Jan. 2006.

[7] T. Le Toan, F. Ribbes, L.-F. Wang, N. Floury, K.-H. Ding, J. A. Kong, M. Fujita, and T. Kurosu, "Rice crop mapping and monitoring using ERS-1 data based on experiment and modeling results," IEEE Trans. Geosci. Remote Sens., vol. 35, no. 1, pp. 41-56, Jan. 1997.

[8] L.-F. Wang, J. A. Kong, K.-H. Ding, T. Le Toan, F. Ribbes-Baillarin, and N. Floury, "Electromagnetic scattering model for rice canopy based on Monte Carlo simulation," Prog. Electromagn. Res., vol. 52, pp. 153-171, 2005.

[9] T. Kurosu, M. Fujita, and K. Chiba, "Monitoring of rice crop growth from space using the ERS-1 C-band SAR," IEEE Trans. Geosci. Remote Sens., vol. 33, no. 4, pp. 1092-1096, Jul. 1995.

[10] F. Ribbes and T. Le Toan, "Rice field mapping and monitoring with RADARSAT data," Int. J. Remote Sens., vol. 20, no. 4, pp. 745-765, Mar. 1999.

[11] Y. Shao, X. Fan, H. Liu, J. Xiao, S. Ross, B. Brisco, R. Brown, and G. Staples, "Rice monitoring and production estimation using multitemporal RADARSAT," Remote Sens. Environ., vol. 76, no. 3, pp. 310-325, Jun. 2001.

[12] M. Chakraborty, S. Panigrahy, and S. A. Sharma, "Discrimination of rice crop grown under different cultural practices using temporal ERS-1 synthetic aperture radar data," ISPRS J. Photogramm. Remote Sens., vol. 52, no. 4, pp. 183-191, Aug. 1997.

[13] M. Chakraborty, K. R. Manjunath, S. Panigrahy, N. Kundu, and J. S. Parihar, "Rice crop parameter retrieval using multi-temporal, multiincidence angle Radarsat SAR data," ISPRS J. Photogramm. Remote Sens., vol. 59, no. 5, pp. 310-322, Aug. 2005.

[14] C. Chen and H. McNairn, "A neural network integrated approach for rice crop monitoring," Int. J. Remote Sens., vol. 27, no. 7, pp. 1367-1393, Apr. 10, 2006.

[15] J. Aschbacher, A. Pongsrihadulchai, S. Karnchanasutham, C. Rodprom, D. R. Paudyal, and T. Le Toan, "Assessment of ERS-1 SAR data for rice crop mapping and monitoring," in Proc. IGARSS, Firenze, Italy, 1995, pp. 2183-2185.

[16] S.-A. Kaojarern, J.-P. Delsol, T. Le Toan, and K. Suan Pheng, "Assessment of multi-temporal radar imagery in mapping land system for rainfed lowland rice in Northeast Thailand," Asian J. Geoinformatics, vol. 2, no. 4, pp. 29-44, Jun. 2002.

[17] S. C. Liew, S.-P. Kam, T.-P. Tuong, P. Chen, V. Q. Minh, and H. Lim, "Application of multitemporal ERS-2 synthetic aperture radar in delineating rice cropping systems in the Mekong River Delta, Vietnam," IEEE Trans. Geosci. Remote Sens., vol. 36, no. 5, pp. 1412-1420, Sep. 1998.

[18] N. Lam Dao, T. Le Toan, and N. Floury, "The use of SAR data for rice crop monitoring, a case study of Mekong river delta-Vietnam," in Proc. Asian Conf. Remote Sens., Hanoi, Vietnam, 2005.

[19] Y. Inoue, T. Kurosu, H. Maeno, S. Uratsuka, T. Kozu, K. Dabrowska-Zielinska, and J. Qi, "Season-long daily measurements of multifrequency ( $\mathrm{Ka}, \mathrm{Ku}, \mathrm{X}, \mathrm{C}$, and $\mathrm{L})$ and full-polarization backscatter signatures over paddy rice field and their relationship with biological variables," Remote Sens. Environ., vol. 81, no. 2/3, pp. 194-204, Aug. 2002.

[20] C. Indrani, M. Chakraborty, and J. S. Parihar, "Estimation of rice growth parameter and crop phenology with conjunctive use of RADARSAT and ENVISAT," in Proc. Envisat Symp., Montreux, Switzerland, 2007.

[21] J. Chen, H. Lin, and Z. Pei, "Application of ENVISAT ASAR data in mapping rice crop growth in Southern China," IEEE Geosci. Remote Sens. Lett., vol. 4, no. 3, pp. 431-435, Jul. 2007.
[22] General Statistics Office of Vietnam, Structure of Used Land by Province. [Online]. Available: http://www.gso.gov.vn/default_en.aspx?tabid= 466\&idmid $=3 \&$ Item $\mathrm{ID}=6135$

[23] B. Rosich and P. Meadows, European Space Agency, Absolute Calibration of ASAR Level 1 Products Generated With PF-ASAR. Technical Note. [Online]. Available: http://earth.esa.int/pub/ESA_DOC/ ENVISAT/ASAR/ASAR_products_absolute_calibration_v1.5.pdf

[24] E. Rignot and J. van Zyl, "Change detection techniques for ERS-1 SAR data," IEEE Trans. Geosci. Remote Sens., vol. 31, no. 4, pp. 896-906, Jul. 1993.

[25] S. Quegan and J. J. Yu, "Filtering of multichannel SAR images," IEEE Trans. Geosci. Remote Sens., vol. 39, no. 11, pp. 2373-2379, Nov. 2001.

[26] General Statistics Office of Vietnam, Agriculture, Fishery and Fishery Statistical Data. [Online]. Available: http://www.gso.gov.vn/ default_en.aspx?tabid $=469 \&$ idmid $=3$

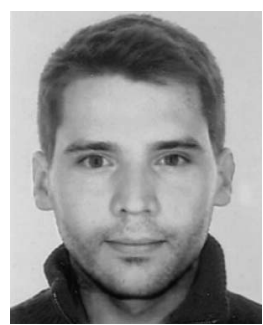

Alexandre Bouvet was born in France, in 1981. $\mathrm{He}$ received the B.S. degree in engineering from the Ecole Nationale Superieure d'Aeronautique et de l'Espace, Toulouse, France, in 2004. He is currently working toward the Ph.D. degree on the monitoring of rice paddies from space at the Centre d'Etudes Spatiales de la Biosphère, Toulouse.

His interests include synthetic aperture radar (SAR) image processing and the use of SAR remote sensing data in land applications.

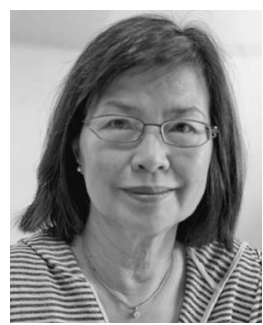

Thuy Le Toan received the Ph.D. degree in nuclear physics from the Paul Sabatier University, Toulouse, France.

Since 1995, she has been with the Centre d'Etudes Spatiales de la Biosphère, Toulouse, where she is leading research activities in the area of microwave remote sensing applied to natural surfaces, including experimentation and modeling of microwave interaction with agricultural and forested media. Her current interest is on the use of remote sensing data to quantify the effect of land processes on the carbon cycle. She has been a Project Coordinator and Principal Investigator on several synthetic aperture radar (SAR) campaigns and projects dealing with spaceborne SARs. She is leading current projects using the Environmental Satellite/ Advanced SAR for rice monitoring in Vietnam and China (the European Space Agency (ESA)-China Ministry of Science and Technology Dragon rice project), and projects using Advanced Land Observing Satellite (ALOS) Phased Array type L-band SAR (PALSAR) for forest observations. She is conducting studies to assess P-band SAR for forest biomass retrieval.

Dr. Le Toan is member of the ALOS Kyoto and Carbon Science team, and the Chairperson of the BIOMASS Mission Assessment Group, working toward the phase A selection by ESA for the next Earth Explorer Core mission.

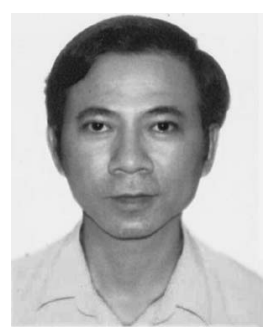

Nguyen Lam-Dao received the Engineering degree in geodesy from Ho Chi Minh City University of Technology, Ho Chi Minh City, Vietnam, and the M.E. degree in remote sensing and geographic information systems from Asian Institute of Technology, Thailand, in 1996. He is currently working toward the Ph.D. degree in radar remote sensing of vegetation at the University of Southern Queensland, Toowoomba, Australia, and Vietnam National University, Ho Chi Minh City.

Since 1990, he has been with the Center for Space Physics and Remote Sensing Technology, Ho Chi Minh City, Vietnam. The current name of the center is GIS and Remote Sensing Research Center, Ho Chi Minh City Institute of Resources Geography. His research interests include experimental analysis and image processing toward applications. 